\title{
Abnormal $Q$ waves in right sided chest leads provoked by onset of right bundle-branch block in patients with anteroseptal infarction
}

\author{
MAURICIO B ROSENBAUM, LUIS A GIROTTI, JULIO O LAZZZARI, M SUSANA HALPERN, \\ MARCELO V ELIZARI
}

From the Service of Cardiology, Ramos Mejia Hospital, Buenos Aires, Argentina

SUMMARY In five cases of anteroseptal myocardial infarction complicated by intermittent right bundle-branch block, the onset of right bundle-branch block provoked the appearance of abnormal $Q$ waves in leads V1 and V2, whereas a small initial $R$ wave was present in the same leads during normal conduction. The intermittency of the conduction disturbance indicated that the $Q$ waves were "right bundle-branch block dependent". It was also apparent that right bundle-branch block shifted the electrical location of the infarct towards the right, and made it look much larger. Right bundle-branch block dependent $Q$ waves may arise during the acute stage of an anterior infarct suggesting, fallaciously, that an acute extension has occurred, or during the chronic stage, leading to the erroneous supposition that a new infarct has developed. The abnormal $Q$ waves of anteroseptal infarction complicated by fixed right bundle-branch block, though obviously related to the infarct, may be dependent on the right bundle-branch block.

In some patients with anteroseptal myocardial infarction, we have observed that the onset of right bundle-branch block may cause the appearance of abnormal $Q$ waves in leads V1 and V2, by turning an $\mathrm{rS}$ pattern into a $\mathrm{QR}$. Though the septal involvement becomes more readily apparent, the mere occurrence of right bundle-branch block may give rise to erroneous diagnosis of a new infarct or an extension of a previous one. Five cases showing this electrocardiographic sign are presented in this paper, and four previously reported cases ${ }^{1-3}$ are reviewed.

\section{Case reports}

CASE 1

A 48-year-old man had suffered an acute anterior wall myocardial infarction complicated by intermittent right bundle-branch block 10 months previously. Fig. 1 shows the full conventional electrocardiogram with right bundle-branch block. In the lower strip, two postextrasystolic beats disclose a normally con-

This work was supported in part by the Fundacion de Investigaciones Cardiologicas Einthoven and the Comisión para el Estudio Integral de la enfermedad de Chagas.

Accepted for publication 6 November 1981 ducted $Q R S$ in which a small initial $R$ wave can be seen, whereas the right bundle-branch block beats were all characterised by the presence of a deep $Q$
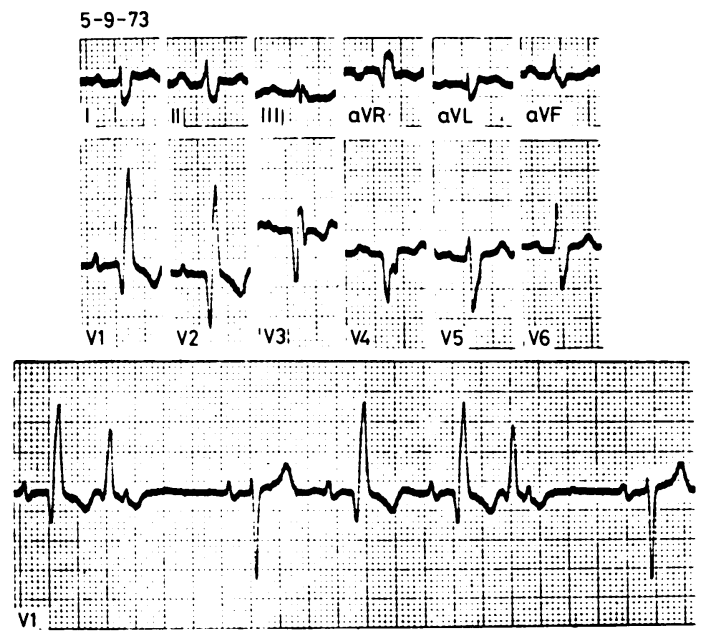

Fig. 1 Case 1, 10 months after the acute episode. Right bundle-branch block and anterior myocardial infarction. Lower strip shows the appearance of right bundle-branch block dependent $Q$ waves in lead $V 1$. 
wave. It was apparent that the $\mathrm{Q}$ wave in $\mathrm{V} 1$ was right bundle-branch block dependent. Fig. 2 shows two electrocardiograms recorded during the acute stage, illustrating that at that time the $Q$ wave occurred both with or without right bundle-branch block. The $R$ wave in V1 (during normally conducted beats) was first seen to occur several months after the acute episode, suggesting that tissue somewhere in the infarcted area had recovered from the ischaemic process. The patient died four years later because of recurrent pulmonary embolism. A routine necropsy showed an old transmural anterior and septal myocardial infarction. The right ventricular free wall was not involved.

CASE 2

A 50-year-old man developed an acute anterior wall myocardial infarction and intermittent right bundlebranch block. Four electrocardiograms were selected (Fig. 3) to illustrate that $Q$ waves occurred in leads V1 to V4 only when right bundle-branch block was present (B and D), while a small $R$ wave appeared in the same leads when right bundle-branch block was absent (A and C). Right bundle-branch block conveyed the impression that the infarct was larger and that its electrical location was shifted towards the right. Though transient additional ischaemic injury causing both the right bundle-branch block and the $Q$ waves cannot be totally excluded, such a possibility is less likely than the simple occurrence of right bundle-branch block dependent $Q$ waves, because disappearance of the right bundle-branch block was repeatedly and instantaneously followed by reappearance of $R$ waves. Subsequently the patient developed left bundle-branch block, paroxysmal atrioventricular
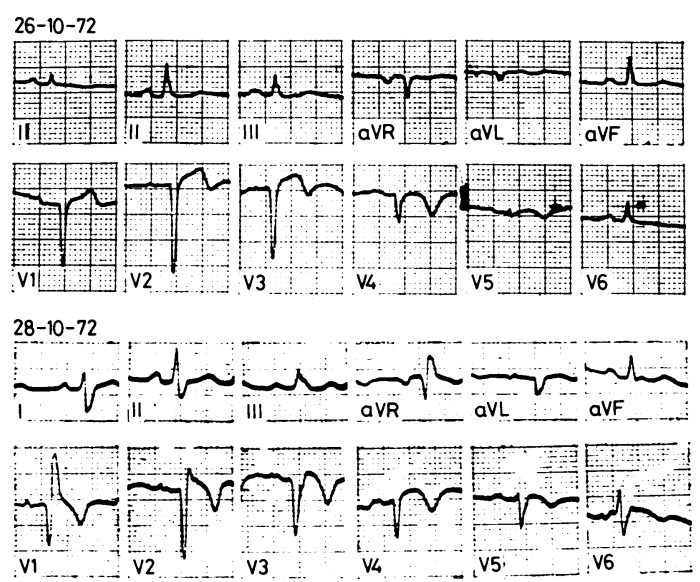

Fig. 2 Case 1, during the acute stage of an anterior myocardial infarction. At this time $Q$ waves are seen in the normal conducted as well as in the right bundle-branch block beats.
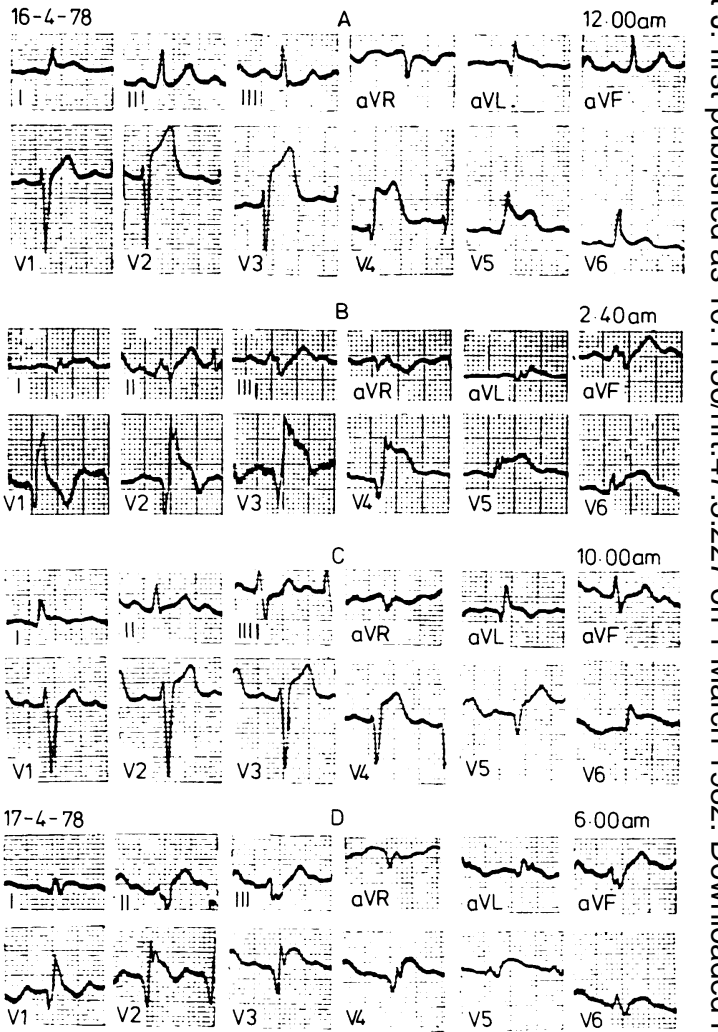

Fig. 3 Case 2, during the acute stage of an anterior myocardial infarction. Abnormal $Q$ waves in leads V1 to V4 are clearly seen only when right bundle-branch block is present (Band D). When the right bundle-branch block disappears ( $A$ and $C$ ) those $Q$ waves are replaced by conspicuous $R$ waves.

block, and recurrent ventricular tachycardia, and died on the eighth day. No necropsy was obtained.

\section{CASE 3}

Fig. 4 shows four electrocardiograms recorded from 윽 an 81-year-old woman within the space of six hours. $\frac{D}{2}$ There is an acute anterior myocardial infarction with left anterior hemiblock, and right bundle-branch o block occurs in the second electrocardiogram but not $N$ in the first and third tracings. During right bundle- $N$ branch block abnormal $\mathrm{Q}$ waves appear in leads $\mathrm{V} 1 \mathrm{\omega}$ to V5 but not in leads I, aVL, and V6. Conversely, a small $\mathrm{R}$ wave is seen in V1 to V3 and Q waves occur in $\mathrm{I}, \mathrm{aVL}$, and V6 when right bundle-branch block is $\underset{\oplus}{\mathbb{D}}$ absent. Right bundle-branch block produces abnor- mal $\mathrm{Q}$ waves in right sided chest leads and "shifts the $\frac{0}{0}$ infarct towards the right", simulating an acute exten- $\frac{O}{\mathrm{D}}$ sion. The fourth electrocardiogram shows that even a $\stackrel{\rho}{\stackrel{\circ}{\circ}}$ small degree of incomplete right bundle-branch block $\AA$ evoked the right bundle-branch block dependent $\mathrm{Q} \mathcal{O}$ 


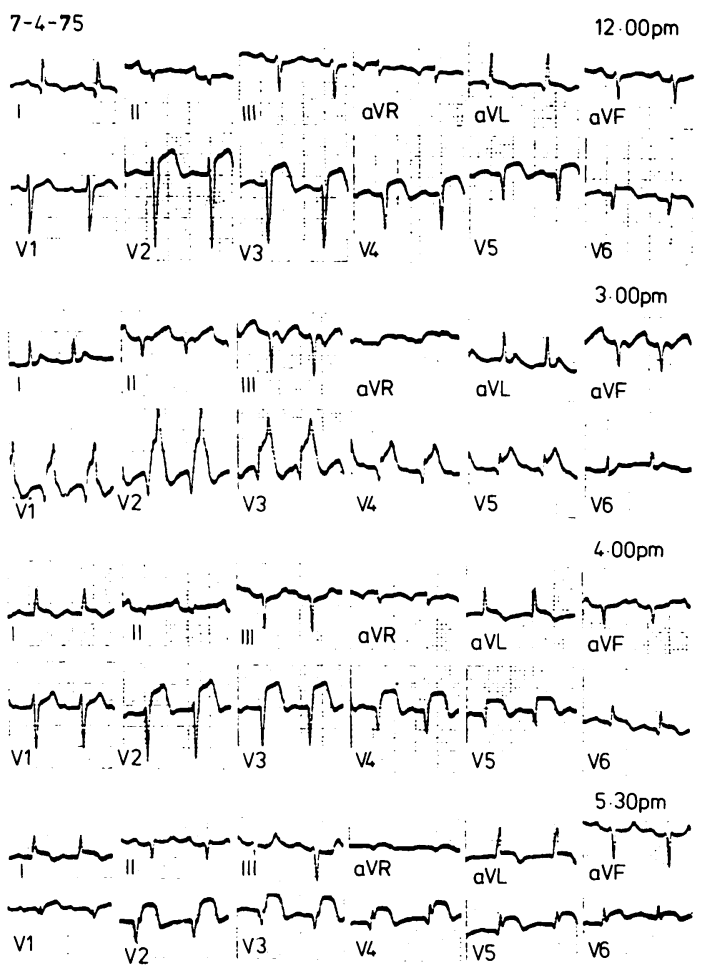

Fig. 4 Case 3. The four electrocardiograms were taken during the acute stage of an anterior infarction. Complete (second ECG) as well as incomplete right bundle-branch block (fourth ECG) produces $Q$ waves in the precordial leads VI to V5.

waves. The patient died in cardiogenic shock three hours later. Necropsy showed total obstruction of the anterior descending coronary artery close to its origin and an acute transmural myocardial infarction involving the anterolateral wall of the left ventricle and nearly the entire ventricular septum. The right ventricle was spared.

\section{CASE 4}

A 39-year-old man had suffered an acute anteroseptal myocardial infarction. The first tracing obtained 48 hours after the acute episode showed right bundlebranch block, left anterior hemiblock, and abnormal $\mathrm{Q}$ waves in leads V1 to V3. A second electrocardiogram, 24 hours later, showed disappearance of the right bundle-branch block which coincided with restoration of a small $\mathrm{R}$ wave in $\mathrm{V} 1$ to $\mathrm{V} 3$ and more conspicuous $\mathrm{Q}$ waves in I and aVL. A third electrocardiogram was recorded three years later. Without any further episode of chest pain, right bundlebranch block had recurred and was again accompanied by abnormal Q waves in V1 to V3, while $\mathrm{Q}$ was absent from I and much smaller in aVL. In a previous publication, ${ }^{4}$ this was interpreted as indicating the development of a new anteroseptal infarct complicated again by right bundle-branch block. It seems now more likely, however, that what the patient actually developed was right bundlebranch block, which elicited the "new" $Q$ waves and the apparent shift of the infarct towards the right.

\section{CASE 5}

The three electrocardiograms in Fig. 5 were recorded from a 61-year-old man 34 hours after a prolonged episode of retrosternal pain. The tracing at 1700 hours shows right bundle-branch block, left anterior hemiblock, and abnormal Q waves in V1 to V2, denoting an anteroseptal infarction. A QS in III and aVF is compatible with involvement of the inferior wall. At 1430 and 1710 hours right bundle-branch block was absent and initial $R$ waves were present in V1 to V6. It should be noted that frank ST segment elevation did not occur in any of the electrocardiograms, so that in the absence of right bundle-branch block the anterior infarct was not clearly apparent. The next day the patient developed left bundle-branch block followed shortly by complete atrioventricular block and died on the third day. Necropsy disclosed a massive anterolateral, inferior, and septal myocardial infarction (Fig. 6). The entire septum was necrotic but for a small subendocardial rim on the right below the pars membranacea. Careful study of many histological sec-
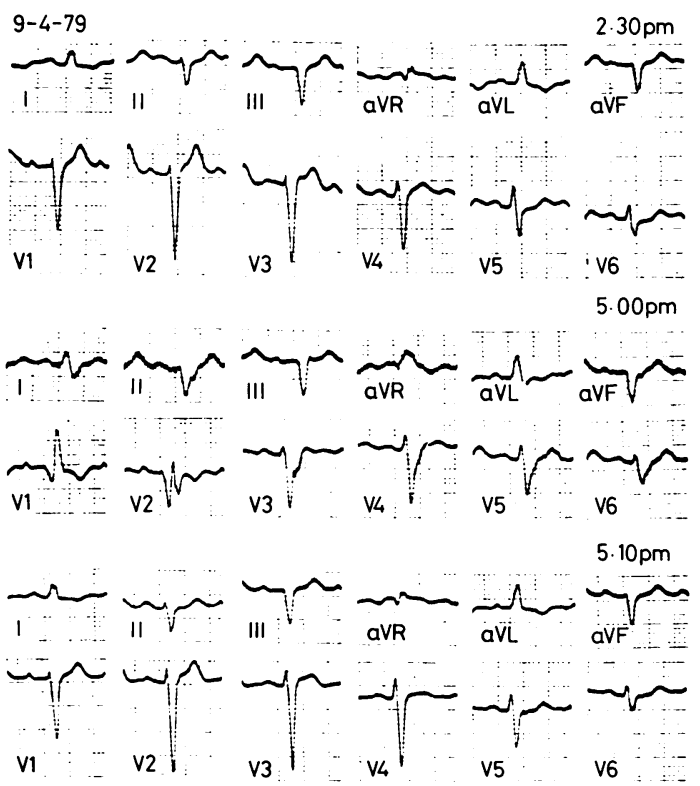

Fig. 5 Case 5. The three electrocardiograms were recorded during an acute coronary episode. $Q$ waves denoting an anteroseptal infarction are only seen when right bundle-branch block is present. 


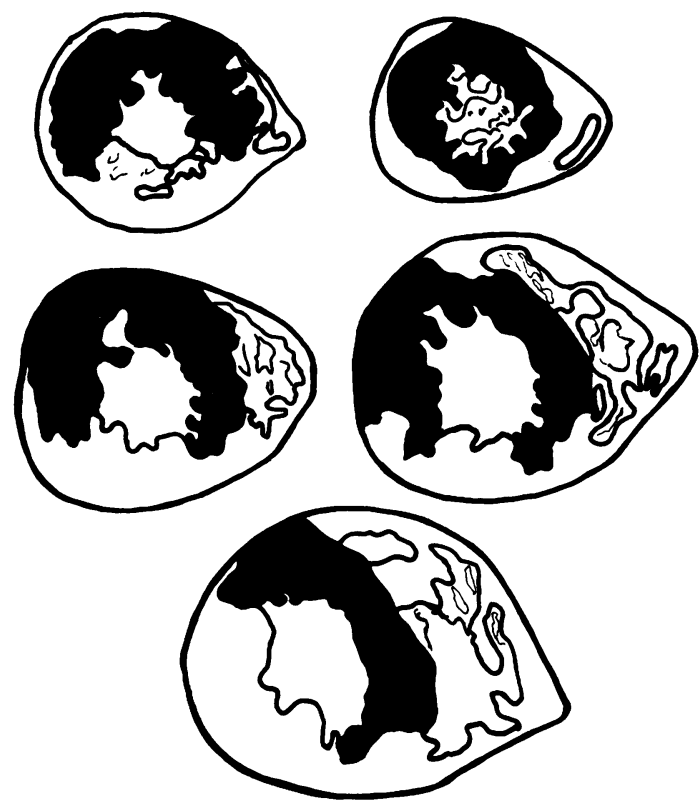

Fig. 6 Case 5. Necropsy findings. Serial sections of the heart showed a massive anterolateral inferior and septal myocardial infarction, without any right ventricular involvement (in black necrotic areas).

tions failed to show any evidence of right ventricular involvement.

\section{Discussion}

MECHANISM OF RIGHT BUNDLE-BRANCH BLOCK DEPENDENT Q WAVES

For many years it has been acknowledged that right bundle-branch block does not alter the direction of the early QRS forces. ${ }^{1}$ This depends on the fact that septal activation takes off from the left septal surface $^{45}$ because of earlier arrival of the impulse coming down the left bundle-branch. ${ }^{6}$ Accordingly, $Q$ waves tend to disappear in left bundle-branch block, and do not change (or do not occur if previously absent) in right bundle-branch block. Though disputed by some, ${ }^{7-9}$ the many cases of intermittent right bundle-branch block and left bundle-branch block reported by various authors, ${ }^{4-1011}$ show this mechanism to be true under a wide variety of clinical conditions. The five cases presented in this paper are an exception to the rule, and the fact that the occurrence of right bundle-branch block dependent $Q$ waves was related to anterior and septal myocardial infarction suggests that the mechanism was probably similar in all of them. In our cases initial R waves in V1 and V2 were present during normal conduction but not during right bundle-branch block, suggesting that they represented activation of part of the heart $c$ "served" by the right bundle-branch, probably the thin anterior wall of the right ventricle. We postulate $\stackrel{\text { S }}{+}$ that a transmural septal infarction cancelled out the normal septal force and made it possible for a small $\overline{\bar{\omega}}$. normally ineffectual electrical force of right ventricu- $-\frac{\bar{s}}{\sigma}$ lar origin to become apparent as a small $R$ wave in $V 1 \stackrel{\Phi}{\AA}$ and V2, and that right ventricular infarction would $\%$ make this phenomenon less likely to occur. This $\vec{\circ}$ hypothesis is supported by the fact that in our three ${ }_{-}$ patients who were examined at necropsy septal infarc- $\vec{\omega}$ tion was transmural and right ventricular involvement $\stackrel{\odot}{\curvearrowright}$ was absent, and by the evidence that anteroseptal infarcts usually fail to extend to the right ventricle. ${ }^{12}+$ Under such conditions, the abnormal $Q$ waves in V1 $\omega$ and V2 may only occur if right bundle-branch block is present. Though left anterior hemiblock occurred in $V$ four of our cases, it was unrelated to the $Q$ waves in 9 V1 and V2. In case 1 the $Q$ waves occurred without left anterior hemiblock; in cases 2 and 4 right 3 bundle-branch block elicited the $Q$ waves both in the $\overline{\frac{T}{3}}$ presence or absence of left anterior hemiblock; and in cases 3 and 5 the $Q$ waves were absent during isolated $\oplus_{\infty}$ left anterior hemiblock and only occurred when right ${ }^{\circ}$ bundle-branch block appeared. In addition, no other known form of fascicular block was apparent in the electrocardiograms showing the abnormal $Q$ waves. $\bar{O}$ An alternative explanation would be a transient myocardial injury causing both the right bundle- $\stackrel{\Phi}{\propto}$ branch block and the $Q$ waves. In fact, it has been $\overrightarrow{\vec{P}}$ reported that $Q$ waves may occur only transiently dur- $\frac{O}{3}$ ing acute episodes of coronary insufficiency. ${ }^{13-16} \supset$ This was not the case, however, in case 1 , in whom right bundle-branch block was intermittent under chronic conditions; it was unlikely in cases 2 and 5 , in whom right bundle-branch block dependent $\mathrm{Q}$ waves? were seen to occur on different occasions; but cannot $\frac{\sigma}{3}$ be totally excluded in cases 3 and 4 . An incomplete left bundle-branch block may justify the occurrence $\frac{O}{3}$ of small $R$ waves in V1 and V2 even in the presence of a septal infarct, and under such conditions right $\frac{}{3}$ bundle-branch block may suppress those $R$ waves. $\frac{P}{2}$ Though this latter mechanism may eventually be operative in other cases, it did not seem to participate $N$ in the present series, with the possible exception of ${ }_{N}^{-}$ case 5 .

ROLE OF RIGHT VENTRICLE

A normally activated right ventricle is a necessary 0 condition for the occurrence of initial $R$ waves in V1 $\mathbb{D}$ and V2 in the presence of a transmural septal infarc- + tion and, as a consequence, for the occurrence of right $\frac{T}{0}$ bundle-branch block dependent $Q$ waves. This does $\frac{}{\mathbb{1}}$ not explain, however, the cases in which an anterosep- $\frac{\rho}{\mathbb{Q}}$ tal myocardial infarction causes abnormal $Q$ waves $\stackrel{\mathbb{Q}}{Q}$ either with or without right bundle-branch block. For 
example, in case 1 the $Q$ waves were not right bundle-branch block dependent during the acute stage (Fig. 2), and it was only when the small $R$ waves reappeared in the chronic stage (Fig. 1) that the $Q$ waves became right bundle-branch block dependent. In fact, if the small $\mathbf{R}$ waves which disappear during right bundle-branch block are of right ventricular origin, their absence during normal conduction must necessarily suggest some right ventricular involvement. It is then reasonable to assume that in anteroseptal myocardial infarction in general, a $Q S$ in V1 and V2 may indicate additional right ventricular damage, and reappearance of the $R$ waves may suggest recovery of a tissue which because of its anatomical features (the much thinner wall) or peculiarities of its blood supply 12 may more readily survive from the ischaemic insult than the septum and left ventricle. This possibility, which requires more precise anatomical studies for confirmation, finds support in the studies by Myers et al. ${ }^{1718}$ showing that large anterior and septal infarcts may, though not often, involve the anterior wall of the right ventricle.

INCIDENCE OF RIGHT BUNDLE-BRANCH BLOCK DEPENDENT Q WAVES

Right bundle-branch block dependent $Q$ waves may be more common than previously suspected. In 1962 Szilagyi and Ginsburg ${ }^{2}$ reported a case under the title of "Acute myocardial infarction revealed in the presence of right bundle-branch block". In a classic paper by Wilson et al. ${ }^{1}$ a case of anterior infarction complicated by transient right bundle-branch block is illustrated (their Fig. 19), showing that $Q$ waves in leads V1 to V4 were present during right bundle-branch block, while a small $\mathbf{R}$ wave occurred during normal conduction. The authors pointed out that the "small initial $R$ waves . . . apparently represent activation of the free wall of the right ventricle". Two examples of right bundle-branch block dependent $\mathrm{Q}$ waves were reported by Gambetta and Childers, ${ }^{3}$ though they interpreted the "rate-dependent right precordial Q waves" as a manifestation of "septal focal block". In one of the patients late reappearance of right bundlebranch block led to readmission to hospital because a new infarct was simulated. More important than the individual cases which require intermittency of the right bundle-branch block to be unveiled is the fact that anterior infarction complicated by right bundlebranch block is almost invariably accompanied by abnormal $\mathrm{Q}$ waves in $\mathrm{V} 1$ and $\mathrm{V} 2^{1}$ while uncomplicated anteroseptal infarction commonly displays small $R$ waves in the same leads. In a study by Myers $e t$ al. ${ }^{19} 12$ of 20 necropsy proven cases of anteroseptal infarction showed small $R$ waves in V1 and V2. Of course, it may be argued that the $Q$ waves more readily seen in the presence of right bundle-branch block are simply the result of a larger infarct. Though this may certainly be so, the fact remains that in an unknown number of cases of anterior infarction with right bundle-branch block the abnormal $Q$ waves in V1 and V2 may depend to a great extent on the right bundle-branch block.

\section{CLINICAL IMPLICATIONS}

In some cases of anteroseptal myocardial infarction the diagnosis can only or more readily be made in the presence of right bundle-branch block. Right bundle-branch block seems to "expand and shift the infarct towards the right". Since this phenomenon occurs in association with large anteroseptal infarcts, it may be said that right bundle-branch block conveys a more correct impression of the extension of the infarct. During the acute stage the onset of right bundle-branch block may incorrectly suggest an extension of a recent anterior myocardial infarction. In the chronic stage the occurrence of right bundlebranch block may cause $\mathrm{Q}$ waves to appear in V1 and V2 and lead to an erroneous conclusion that a new infarct has developed. These are the most important mistakes that can be incurred by overlooking the electrocardiographic sign discussed in this paper.

We are indebted to Dr Jose Milei for the anatomical study performed on case 5 .

\section{References}

1 Wilson FN, Rosenbaum FF, Johnston FD. Interpretation of the ventricular complex of the electrocardiogram. In: Dock W, Snapper I, eds. Advances of internal medicine. vol. 2. New York: Interscience, 1947: 1-63.

2 Szilagyi N, Ginsburg M. Acute myocardial infarction revealed in the presence of right bundle-branch block and ventricular extrasystoles. Am $\mathcal{F}$ Cardiol 1962; 9: 632-8.

3 Gambetta M, Childers RW. Rate-dependent right precordial Q waves: "septal focal block". Am f Cardiol 1973; 32: 196-201.

4 Lewis T, Rothschild MA. The excitatory process in the dog's heart. Part II. The ventricles. Philos Trans $R$ Soc Lond 1915; 206: 181-206.

5 Durrer D, Van Dam RT, Freud GE, Janse MJ, Meijler FL, Arzbaecher RC. Total excitation of the isolated human heart. Circulation 1970; 41: 899-912.

6 Rosenbaum MB, Elizari MV, Lazzari JO. The hemiblocks. Oldsmar, Florida: Tampa Tracings, 1970.

7 Amer NS, Stuckey JH, Hoffman BF, Cappelletti RR, Domingo RT. Activation of the interventricular septal myocardium studied during cardiopulmonary bypass. Am Heart f 1960; 59: 224-37.

8 Rosen KM, Rahimtoola SH, Sinno MZ, Gunnar RM. Bundle branch and ventricular activation in man: a study utilizing catheter recordings of left and right bundlebranch potentials. Circulation 1971; 43: 193-201. 
9 Narula OS. Intraventricular conduction defects. In: $H$ is Bundle electrocardiography and clinical electrophysiology. New York: FA Davis, 1975.

10 Grant RP, Dodge HT. Mechanisms of QRS complex prolongation in man, left ventricular conduction disturbances. Am F Med 1956; 20: 834-52.

11 Dodge HT, Grant RP. Mechanisms of QRS complex prolongation in man, right ventricular conduction defects. Am F Med 1956; 21: 534-50.

12 Isner JM, Roberts WC. Right ventricular infarction complicating left ventricular infarction secondary to coronary heart disease. Frequency, location, associated findings and significance from analysis of 236 necropsy patients with acute or healed myocardial infarction. Am $\mathcal{F}$ Cardiol 1978; 42: 885-94.

13 Bayley RH, La Due JS. Differentiation of the electrocardiographic changes produced in the dog by prolonged temporary occlusion of a coronary artery from those produced by post-operative pericarditis. Am Heart $\mathcal{F}$ 1944; 28: $233-46$.

14 Zuckermann R, Cabrera E, Estandía A, Barbato E, Zamora J. Infarto miocárdico y tensión arterial. I. Estudio electrocardiografico experimental. Arch Inst Cardiol Mex 1949; 19: 55-68.
15 Gross H, Rubin IL, Laufer H, Bloomberg AE, Bujdoso $\subseteq$. L, Delman AJ. Transient abnormal Q waves in the dog $\vec{F}$ without myocardial infarction. Am $\mathcal{F}$ Cardiol 1964; 14: 669-74.

16 Rubin IL, Gross H, Vigliano EM. Transient abnormal Q 들 waves during coronary insufficiency. Am Heart $\mathcal{F} 1966$; 71: 254-9.

17 Myers GB, Klein HA, Hiratzka T. Correlation of electrocardiographic and pathologic findings in large $\infty$ anterolateral infarcts. Am Hean $\mathcal{F}$ 1948; 36: 838-81.

18 Myers GB, Klein HA, Hiratzka T. Correlation of elec- trocardiographic and pathologic findings in infarction of $\vec{\omega}$ the intraventricular septum and right ventricle. Am Heart F 1949; 37: 720-70.

19 Myers GB, Klein HA, Stofer BE. Correlation of electrocardiographic and pathologic findings in anteroseptal $\dot{\omega}$ infarction. Am Heart $\mathcal{f}$ 1948; 36: 535-75.

Requests for reprints to Dr Mauricio B Rosenbaum, $\frac{3}{3}$ Service of Cardiology, Ramos Mejía Hospital, Urquiza 609, Buenos Aires, Argentina (1221). 